\title{
Flow Cytometry and Phytochemical Analysis of a Sunflower Cell Suspension Culture in a 5-L Bioreactor ${ }^{\S}$
}

\author{
Christiane Haas ${ }^{\mathrm{a}}$, Jost Weber ${ }^{\mathrm{a}}$, Jutta Ludwig-Müller ${ }^{\mathrm{b}}$, Sandra Deponte ${ }^{\mathrm{a}}$, \\ Thomas Bley ${ }^{\mathrm{a}}$, and Milen Georgiev ${ }^{\mathrm{a}, \mathrm{c}, *}$ \\ a Institute of Food Technology and Bioprocess Engineering, Dresden University of \\ Technology, Bergstrasse 120, D-01069 Dresden, Germany \\ b Institute of Botany, Dresden University of Technology, Zellescher Weg 20b, D-01062 \\ Dresden, Germany \\ c Present address: Department of Microbial Biosynthesis and Biotechnologies - \\ Laboratory in Plovdiv, The Stephan Angeloff Institute of Microbiology, Bulgarian \\ Academy of Sciences, 26 Maritza Blvd., 4002 Plovdiv, Bulgaria. \\ Fax: +3 59 (0)2 87001 09. E-mail: milengeorgiev@gbg.bg \\ * Author for correspondence and reprint requests \\ Z. Naturforsch. 63c, 699-705 (2008); received March 20/April 24, 2008
}

A cell suspension culture of sunflower (Helianthus annuus), a producer of immunologically active polysaccharides, was cultivated in a 5-L stirred tank bioreactor, operated in batch mode. After some changes in the internal bioreactor design a stable growth of Helianthus cells was achieved and the accumulated biomass reached $15.2 \mathrm{~g} / \mathrm{L}$ (only $\sim 5 \%$ lower compared to the accumulated biomass in shake-flasks). Flow cytometry used for measuring the cell cycle parameters of suspended Helianthus cells did not reveal significant differences between shake-flasks and bioreactor cultivation modes. For both cultivation methods significant enhancement of the percentage of S-phase cells was observed at the beginning of the cultivation process. Concerning the metabolite production the maximum in exopolysaccharides was reached at day 9 of the cultivation period $(1.9 \mathrm{~g} / \mathrm{L})$, while the highest amounts of $\alpha$-tocopherol were accumulated at the beginning of the cultivation process (day 2 of the cultivation). These finding were related to the respective stress levels caused by the inoculation procedure. The kinetic parameters of growth and polysaccharide production as well as the time course of carbon source utilization were monitored and discussed.

Key words: Cell Cycle, Exopolysaccharides, Helianthus annuus, Tocopherol

\section{Introduction}

Plant cell cultures are considered as an attractive alternative to the classical technologies for the production of bioactive compounds (Rao and Ravishankar, 2002). Furthermore, plant in vitro systems appear to be the only source for the production of high value naturally occurring metabolites from rare and threatened plants, which contribute to the global biodiversity conservation (Georgiev et al., 2007). To date large-scale processes for mass production of metabolites have been developed mainly using dispersed plant cell suspensions (Yanpaisan et al., 1998; Kieran, 2001). Cell suspension cultures possess several advanta-

\footnotetext{
$\S$ Part of this work was presented, as posters, at the $17^{\text {th }}$ Annual Meeting of the German Society of Cytometry (DGfZ), October 10-13, 2007, Regensburg, Germany and Sächsischer Biotechnologietag, November 28, 2007, Dresden, Germany.
}

ges over other plant in vitro systems, for example their resemblance to microbial producers, which allow utilization of well-known bioreactor designs (in some cases with slight modification), easy aseptic inoculation, and higher growth rates. A disadvantage is that plant cells in suspension cultures are very heterogeneous and genetically unstable (Zhong, 2001). From an engineering perspective, the successful application of plant cell suspensions requires large-scale processing technology which supports high-density cultivation of high-yielding, stable cell lines (Kieran, 2001). Cell line selection is frequently used as a powerful tool for both establishment of homogeneous lines and enhancement of metabolite accumulation (Georgiev et al., 2006). Another major point is the development of on-/off-line methods for the determination of cell growth and the physiological behaviour of the cells during their cultivation in different systems. Recently flow cytometry became a popular method for ploidy screening, detection of mixoploidy and 
aneuploidy, cell cycle analysis, estimation of absolute DNA amount or genome size (Yanpaisan et al., 1998, 1999) and thus could be used for biomonitoring.

A cell suspension culture of sunflower (Helianthus annuus) was found to produce extracellular polysaccharides (exopolysaccharides) with immunostimulating properties. They induce migration of peritoneal exudative cells (possessing high bactericidic activity), especially peritoneal macrophages, into the peritoneal cavity of experimental animals (Kratchanova et al., 1996). In a previous study a cell suspension culture of Helianthus annuus was cultivated in shake-flasks, and based on the achieved growth behaviour and metabolite activity the cell producer was evaluated as promising (Pavlov et al., 2005) and therefore could be used as a good model system. Thus, the present study was conducted to investigate the further bioreactor cultivation with respect to both growth of the cells and metabolites accumulation/production (exopolysaccharides and $\alpha$-tocopherol). Flow cytometry was used to study the physiological properties of suspended Helianthus cells cultivated in a stirred bioreactor vessel.

\section{Materials and Methods}

\section{Helianthus annuus cell culture}

A callus culture from Helianthus annuus was provided by courtesy of Prof. Dr. M. Ilieva (Laboratory of Applied Microbiology and Biotechnology, Institute of Microbiology, Bulgarian Academy of Sciences, Plovdiv, Bulgaria). The callus culture was maintained on Linsmayer and Skoog (LS) medium (Duchefa, Haarlem, The Netherlands, Cat. No. L0230), supplemented with $30 \mathrm{~g} / \mathrm{L}$ sucrose, $0.2 \mathrm{mg} / \mathrm{L}$ 2,4-dichlorophenoxyacetic acid and $5.55 \mathrm{~g} / \mathrm{L}$ Phytoagar (Duchefa, Cat. Nos. S0809, D0911, P1003, respectively), during a period of subcultivation of $21 \mathrm{~d}$. The suspension culture was grown and supported in the above described medium without Phytoagar and subcultivated every $8 \mathrm{~d}$.

\section{Bioreactor experimental scheme}

Experiments were performed in a 5-L stirred tank bioreactor (Bioflo III, New Brunswick Scientific, Edison, USA) equipped with two Rushton turbine impellers. For each cultivation, the working volume of the bioreactor was $3 \mathrm{~L}$. LS medium was filled in the reactor and sterilized at $121^{\circ} \mathrm{C}$ for $30 \mathrm{~min}$. After cooling to $26^{\circ} \mathrm{C}$ the medium was inoculated with $20 \%$ (v/v) 8-day-old cell suspension. Agitation speed was fixed at $100 \mathrm{rpm}$ and the air flow rate was consecutively $0.5 \mathrm{~L} / \mathrm{min}$ compressed air (days $0-2$ ) and $1 \mathrm{~L} / \mathrm{min}$ (days 2-11). Control cultivations were performed in $250-\mathrm{mL}$ Erlenmeyer flasks ( $50 \mathrm{~mL}$ net volume) on a shaker at $110 \mathrm{rpm}$, in the dark, at $26^{\circ} \mathrm{C}$.

\section{Cell growth, conductivity and $\mathrm{pH}$ value}

The growth of the cells was monitored through determination of fresh and dry biomass (gravimetrically at $60^{\circ} \mathrm{C}$ for $\sim 24 \mathrm{~h}$ ). The kinetic parameters were determined as follows:

$$
\begin{aligned}
& \partial X / \partial t=\mu_{\max } \cdot X, \\
& \ln X / X_{0}=\mu_{\max } \cdot \Delta t, \\
& \ln X=\mu_{\max } \cdot \Delta t+\ln X_{0},
\end{aligned}
$$

where $X_{0}$ and $X$ are the initial and final cell biomass $(\mathrm{g}), \Delta t$ is the culture time (d) and $\mu_{\max }$ is the maximal growth rate $(1 / \mathrm{d})$.

Following equation (3) the maximal growth rate was determined graphically. The minimal doubling time $\left(t_{\mathrm{d}}\right)$ was calculated as follows:

$$
t_{\mathrm{d}}=\ln 2 / \mu_{\max } \text {. }
$$

The conductivity and the $\mathrm{pH}$ value of the culture medium were determined using conductivity(Qcond 2400 Conductivity Meter Set, VWR International, Darmstadt, Germany) and $\mathrm{pH}$-meters (InnoLab pH720, WTW, Weilheim, Germany).

\section{Sucrose, glucose and fructose determination}

Sucrose, glucose and fructose levels of the culture medium were determined in one batch using an enzyme test kit (R-Pharm, Germany, Cat. No. 10716260035).

\section{Flow cytometry and cell cycle}

A flow cytometer CyFlow ${ }^{\circledR}$ SL blue (Partec, Münster, Germany) with a $488 \mathrm{~nm}$ solid state laser $(20 \mathrm{~mW})$ was used. In order to extract the nuclei from the $H$. annuus cells $\sim 0.53 \mathrm{~g}$ wet biomass was chopped in a Petri dish with a scalpel for $\sim 6 \mathrm{~min}$ in $1.5 \mathrm{~mL}$ Marie's nuclear isolation buffer (Marie and Brown, 1993). The staining occurred by addition of $80 \mu \mathrm{L}$ propidium iodide solution $(1 \mathrm{mg} / \mathrm{mL}$; Fluka, Buchs, Switzerland). After 15 min of incubation at room temperature in the dark the liquid was filtered through a $31 \mu \mathrm{m}$ filter tissue (Poly- 
amid 6.6 monofil, Schwegmann Filtrations-Technik, Grafschaft-Gelsdorf, Germany). The fluorescence was detected through a high-pass filter with a cut-off wavelength of $630 \mathrm{~nm}$ (FL3) and the trigger was set to FL3. For each measurement at least 10,000 nuclei were counted.

\section{Determination of $\alpha$-tocopherol}

The extraction and derivatization method was according to Franke et al. (2007) with slight modifications. Approx. $5 \mathrm{~g}$ frozen biomass were mixed with some granules of 3,5-di-tert-butyl-4-hydroxytoluene (BHT; Sigma-Aldrich, Steinheim, Germany) as an antioxidant and both were grounded in a mortar. The grinding was continued after adding about $10 \mathrm{~mL} n$-hexane (for HPLC; VWR International $\mathrm{BDH}$ Prolabo, Leicestershire, England) and then the mixture was centrifuged at $5,000 \times g$ for $10 \mathrm{~min}$. The upper hexane phase was transferred to a glass test tube with a Pasteur pipette and dried over anhydrous $\mathrm{Na}_{2} \mathrm{SO}_{4}$. The obtained extract was evaporated to dryness (rotary vacuum evaporator) and the formed oily residue was resuspended two times with $0.5 \mathrm{~mL}$ hexane and placed in an Eppendorf tube. After a centrifugation step for $5 \mathrm{~min}$ at $13,000 \times g$ the supernatant was removed carefully and transferred into a glass vial for derivatization. Again the solution was evaporated to dryness under $\mathrm{N}_{2}$, then dissolved in $80 \mu \mathrm{L}$ pyridine (Sigma-Aldrich). To this solution $80 \mu \mathrm{L} \quad N$-methyl- $N$-(trimethylsilyl)trifluoroacetic acid (MSTFA; Sigma-Aldrich) for the silylation were added and the mixture was incubated for $30 \mathrm{~min}$ at $37^{\circ} \mathrm{C}$, followed by $2 \mathrm{~h}$ at room temperature. Subsequently the sample was evaporated to dryness and resuspended in $50 \mu \mathrm{L}$ ethylacetate (for analysis; Riedel de Haën, Seelze, Germany). The sample was transferred into a glass vial for measurement (injection volume was $2 \mu \mathrm{L}$ ). The analysis was performed on a GC-MS Saturn 2100 instrument (Varian, Palo Alto, CA, USA) equipped with a Zebron ZB-5 $(30 \mathrm{~m} \times 0.25 \mathrm{~mm} \times 0.25 \mu \mathrm{m}$; Phenomenex, Aschaffenburg, Germany) GC column. As carrier gas helium was used at a flow rate of $1 \mathrm{~mL} / \mathrm{min}$. Injector temperature was $250{ }^{\circ} \mathrm{C}$ and the temperature program was as follows: $150{ }^{\circ} \mathrm{C}$ for $2 \mathrm{~min}$, then with a heating rate of $25^{\circ} \mathrm{C} / \mathrm{min}$ to $300{ }^{\circ} \mathrm{C}$ and at $300{ }^{\circ} \mathrm{C}$ for $10 \mathrm{~min}$. The retention time of $\alpha$-tocopherol was $10.95 \mathrm{~min}$. Electronimpact ionization was realized at $70 \mathrm{eV}$ and fragments were detected with an ion-trap mass analy- zer. Identification and calculation of endogenous $\alpha$-tocopherol were based on the trace of ion $m / z=503$.

\section{Determination of exopolysaccharides}

The exopolysaccharides (EPS) content was determined following the procedure described by Pavlov et al. (2005). The product formation rate $\left(r_{\text {eps }}\right)$ and specific product formation rate $\left(q_{\text {eps }}\right)$ were calculated according to:

$$
\begin{aligned}
& \Delta \text { EPS } / \Delta t=r_{\mathrm{eps}}=q_{\mathrm{eps}} \cdot X_{\text {mean }}, \\
& X_{\text {mean }}=\Delta X / 2,
\end{aligned}
$$

and the product yield $\left(Y_{\mathrm{eps} / \mathrm{x}}\right)$ according to:

$$
\begin{gathered}
Y_{\text {eps } / \mathrm{x}}=\left(\mathrm{EPS}_{\mathrm{t}=0 \mathrm{~d}}-\mathrm{EPS}_{\mathrm{t}=9 \mathrm{~d}}\right) /\left(X_{\mathrm{t}=0 \mathrm{~d}}\right. \\
\left.-X_{\mathrm{t}=9 \mathrm{~d}}\right)=r_{\mathrm{eps}} / r_{\mathrm{x}} .
\end{gathered}
$$

\section{Statistical analysis of the data}

The data presented are averages from at least three independent experiments. All measurements were repeated in triplicate.

\section{Results and Discussion}

The cultivation of plant in vitro systems in bioreactors represents a critical step in the development and scale-up of technologies for the production of target metabolites. This up-scaling is not always easily accomplished with respect to keep the biosynthetic potential of plant cell suspension cultures (Godoy-Hernandez et al., 2000). The main difficulties appear from the fact that the biosynthesis of desired metabolites is influenced by several factors with different significance to the process, and depends on the cultivation method and physiological peculiarities of the cell culture. In previous experiments it was revealed that Helianthus annuus cell suspension cultures possess stable growth and good exopolysaccharide biosynthetic characteristics (Pavlov et al., 2005). It was also found that during the cultivation in a stirred tank reactor a significant flotation of the cells appeared, which finally hindered the up-scaling process (Werner, 2005). Through several changes in the internal bioreactor design [introduction of a covering silicone tube with number of fine holes for improved aeration and replacement of the propeller impeller by two Rushton turbine impellers (New Brunswick Scientific, Edison, USA)] the flotation was prevented and the system was adjusted for the cultivation of Helianthus cells. 


\section{Growth and physiological characteristics in the bioreactor}

The time course of growth of the Helianthus cells and the medium conductivity changes during the cultivation in the stirred tank reactor were studied (Fig. 1A). It was observed that the culture grew intensively and the maximum of biomass accumulation was reached at the 10th day of cultivation, reaching $15.2 \mathrm{~g} / \mathrm{L}$ (only 5\% lower compared to the accumulated biomass in shake-flasks stage). The maximal growth rate $\left(\mu_{\max }=0.21 / \mathrm{d}\right)$ was ascertained between days 1-7 and the minimal doubling time was $\sim 83 \mathrm{~h}$. Although the calculated kinetic parameters were lower compared to those reported earlier for Helianthus annuus cell suspension cultures, the biomass productivity $(1.5 \mathrm{~g} / \mathrm{L} / \mathrm{d})$ was significantly higher even when an air-lift bioreactor system was used (Scragg, 1990). The conductivity of the medium decreased during the course of the cultivation (Fig. 1A), which is presumably due to the uptake of ionic compounds from the culture medium. It has been shown that the increase in cell concentration could be correlated directly with the decrease in medium conductivity (Ryu and Lee, 1990; Suresh et al., 2001). Such linear interdependence with a high statistical significance $\left(r^{2}=0.99\right)$ was developed for Helianthus cells (Fig. 1D), which could be applied for further fast (compared to the widely used methods) indirect monitoring of cell growth for a better control of biosynthetic processes during the scale-up.

To further characterize the behaviour of the $\mathrm{He}$ lianthus cells in the stirred tank reactor, the time course of the utilization of the carbon source was monitored (Fig. 1B). The sucrose consumption began with a rapid hydrolysis in the culture medium, catalyzed by the cell wall invertase (Shin et al., 2003), being completely exhausted at day 8 of cultivation. In shake-flasks culture some residues could be detected until day 10 (Pavlov et al., 2005), which indicate higher invertase activity in bioreactor cultures. The two monosaccharides glucose and fructose were metabolized in similar temporal patterns being completely utilized at the end of the cultivation process (Fig. 1C).

The time course changes of dissolved oxygen (DO2) were also followed during the cultivation in the stirred tank reactor (Fig. 1C). At the beginning of the cultivation process dissolved oxygen level slightly decreased until day 2 followed by an increase, which was due to the enhancement of the air flow rate (from $0.5 \mathrm{~L} / \mathrm{min}$ to $1.0 \mathrm{~L} / \mathrm{min}$ ). Be-
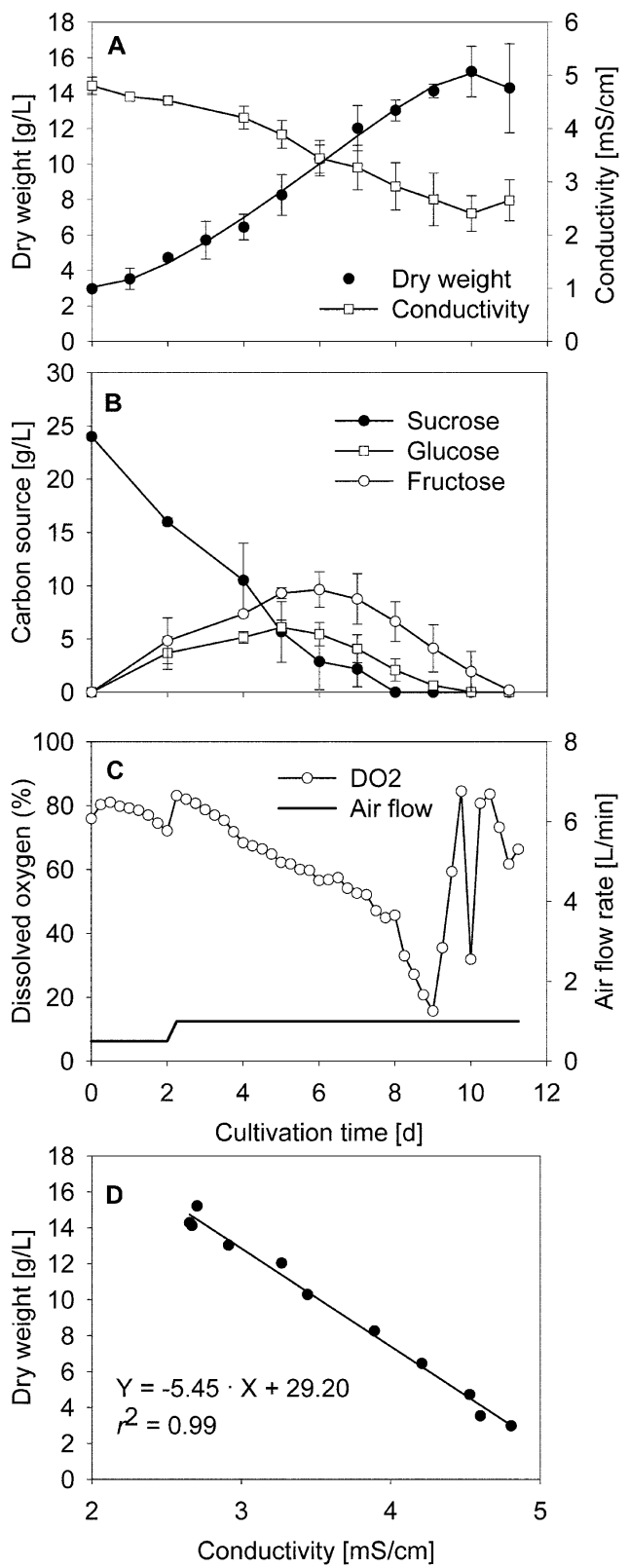

Fig. 1. Time courses of (A) growth and conductivity changes, (B) carbon source utilization, (C) dissolved oxygen and air flow rate changes, and (D) linear dependence between dry weight and conductivity during the cultivation of the Helianthus annuus cell suspension culture in a 5-L stirred tank reactor.

tween days 2-9 the dissolved oxygen level significantly decreased which coincided with the intensive cells growth causing intensive respiration (Fig. 1C). The beginning of the oscillation of the 


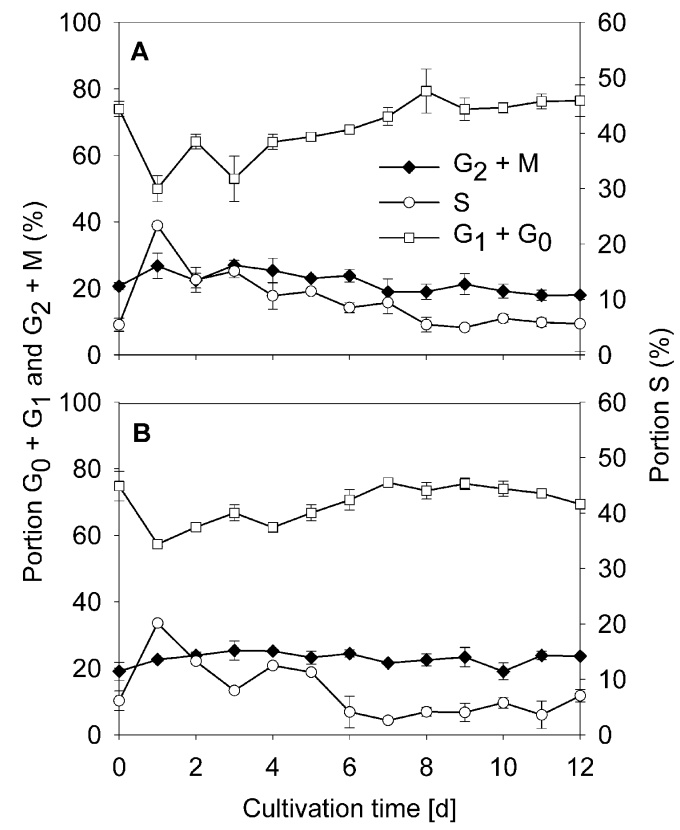

Fig. 2. Portion of the cell population of $\left(\mathrm{G}_{0}+\mathrm{G}_{1}\right)$-, S- and $\left(\mathrm{G}_{2}+\mathrm{M}\right)$-phases during the cultivation of the Helianthus annuus cell suspension culture (A) in shakeflasks and (B) in a 5-L stirred tank reactor.

dissolved oxygen level at day 9 was due to the enhanced culture medium viscosity, which hampered the oxygen mass transfer and exact measurement of the dissolved oxygen level (Schuegerl, 1981).

\section{Cell cycle analyses}

Flow cytometry was used to measure cell cycle parameters in the Helianthus suspension culture (Fig. 2). After the transfer to new medium cell proliferation sets on, the $G_{1}$ stage shortened and cells from $\mathrm{G}_{1}$ enter consecutively to $\mathrm{S}$ - and $\mathrm{G}_{2} / \mathrm{M}$ phases. As a consequence the fraction of $G_{0} / G_{1}$ decreases, which corresponds to the increase of the portions of $S$ and $\mathrm{G}_{2} / \mathrm{M}$. The high percentage of $\mathrm{G}_{2} / \mathrm{M}$ - and S-phase cells was in agreement with the results from culture growth (dry weight curve), where after inoculation there was a period of exponential growth. The highest percentage of $\mathrm{G}_{2} / \mathrm{M}$-phase cells $(27.0 \%)$ was observed on the 3rd day. Subsequently this portion slightly decreased, but never fell below $18 \%$. The percentage of S-phase cells decreased to their start level at day 8 and then remained nearly constant. The $\mathrm{G}_{0} / \mathrm{G}_{1}$-cells had the lowest portion in shake-flasks at the 1 st day with $50 \%$ and increased from the 3rd day continuously, amounting to $\sim 70 \%$ at day 7 (Fig. 2A). Similar results were reported by Yanpaisan et al. (1998) for the cultivation of cell suspension cultures of Solanum aviculare in shake-flasks.

The bioreactor cultivation showed a similar pattern with rather small differences in the cycle phases in the course of the cultivation (Fig. 2B). The biggest differences again could be found shortly after the inoculation. Despite the similar pattern in the time course slight changes were observed - the maximal $\mathrm{G}_{2} / \mathrm{M}$-value was always below the one in shake-flasks $(25.3 \%$ vs. $27.0 \%)$. Consequently, the minimal $\mathrm{G}_{0} / \mathrm{G}_{1}$-value of the bioreactor culture was higher than that for the shake-flasks, which indicates that the cells grow faster in the shake-flasks than in the bioreactor. This was in good agreement with the maximal specific growth rates determined for the corresponding cultivation systems $(0.26$ vs. $0.201 / \mathrm{d}$, respectively) and gave an indication that the $\mathrm{G}_{0} / \mathrm{G}_{1}$-level can be used as a marker for the growth of cells during the cultivation.

If all cells would finish the cell cycle, it could be expected that the amount of cells in the $\mathrm{G}_{2} / \mathrm{M}$ phase would approach to zero at the end of the batch cultivation. However, at the end of the cultivation, we observed a fraction of $\sim 18-24 \%$ $\mathrm{G}_{2} /$ M-phase cells (shake-flasks and bioreactor). This phenomenon could be due to: 1) the existence of quiescent $H$. annuus $\mathrm{G}_{2}$-cells (Sgorbati et al., 1989) and/or 2) a slight tendency of the cells to undergo endoreduplication (genome duplication without mitosis). Endoreduplication is widespread in plants, particularly in angiosperms, and may occur in any cell type except for the gametes, the meristematic and guard cells. Polysomatic cells do not proliferate and hence do not participate in the cell cycle (Cebolla et al., 1999). In this case the cells that underwent one cycle of endoreduplication possess the same DNA amount as the $\left(\mathrm{G}_{2}+\right.$ $\mathrm{M})$-phase cells of the cycling subpopulation. Furthermore it can be assumed that quiescent cells exist in the $\left(G_{0}+G_{1}\right)$-fraction as this fraction never falls below ca. $50 \%$. It should also be noted that the one parameter analysis of DNA content does not provide enough information to distinct cycling form quiescent cells, so further experiments will be focused on biparametric cell cycle analysis. 


\section{Metabolite accumulation and production}

The capacity of a Helianthus annuus cell suspension to produce metabolites was investigated through determination of intracellular (vitamin E) and extracellular (exopolysaccharides) compounds. In a previous study Kratchanova et al. (1996) found that the Helianthus EPS possess high immunostimulating activity. It was also determined that the optimal inoculum amount is $20 \%(\mathrm{v} / \mathrm{v})$. In a more recent study Pavlov et al. (2005) investigated the kinetics of EPS production in shakeflasks stage and outlined the high potential of a Helianthus annuus cell suspension culture for their synthesis. Thus, the time course of EPS production by Helianthus cells was investigated during the cultivation in a 5-L stirred tank reactor (Fig. 3A). It was observed that the active EPS production started at day 4 of the cultivation showing a maximum at day $9(\sim 1.9 \mathrm{~g} / \mathrm{L})$. The product formation rate $\left(r_{\text {eps }}\right)$ and the specific product formation rate $\left(q_{\text {eps }}\right)$ as well as the product yield related to biomass $\left(Y_{\text {eps/x }}\right)$ were determined for the interval of maximal production and are presented in Fig. 3A. The comparison with shake-flasks cultivation showed that all parameters calculated were $\sim 2$-fold lower at the bioreactor stage. Surprisingly for us the levels of some stress-related hormones (jasmonic acid and abscisic acid) were found to be lower in the bioreactor culture than in the shakeflasks one (data not shown) indicating a higher stress situation in flasks, which probably influences the production of EPS as a part of the cell defense system. All of this implicates that the internal bioreactor environment (e.g. air flow rate, agitation speed, temperature) should be optimized to achieve improved high values of EPS production.
$\alpha$-Tocopherol (vitamin E), a compound with high value biological activities, was determined in cultured Helianthus cells by GC-MS. Because of the large diversity of substances present in the $\mathrm{He}$ lianthus sample it was difficult to find an appropriate internal standard for measurements which is not present as natural compound. Therefore we splitted the samples and added a defined amount of $\alpha$-tocopherol to one part and then, by comparing the peak areas of samples with added $\alpha$-tocopherol and unmodified samples, the $\alpha$-tocopherol levels were determined. The values for day 0 were set to $100 \%$ and the other values were normalized to this basis (Fig. 3B). Significant enhancement of the $\alpha$-tocopherol content was observed at the beginning of the cultivation process ( $\sim 3$-fold in shake-flasks culture and 2.6-fold in bioreactor culture). This enhancement could be explained with the higher stress levels, caused by the inoculation procedure and the role of tocopherols as antioxidants. Munne-Bosch and Alegre (2002) proposed that $\alpha$-tocopherol may affect intracellular signaling in plant cells either direct, by interacting with key components of the signaling cascade, or indirect, through the prevention of lipid peroxidation and/or the scavenging of singlet oxygen. Furthermore this supports the statement that the yields of $\alpha$-tocopherol could be increased by subjecting the cells to different stress factors (Gala et al., 2005). From day 2 of cultivation a decreasing trend was observed, probably indicating the decreased stress levels. It should be also noted that the $\alpha$-tocopherol content in the bioreactor culture was almost always higher compared to shake-flasks, which is due to the higher aeration rates and thus the enhanced production of reactive oxygen species.
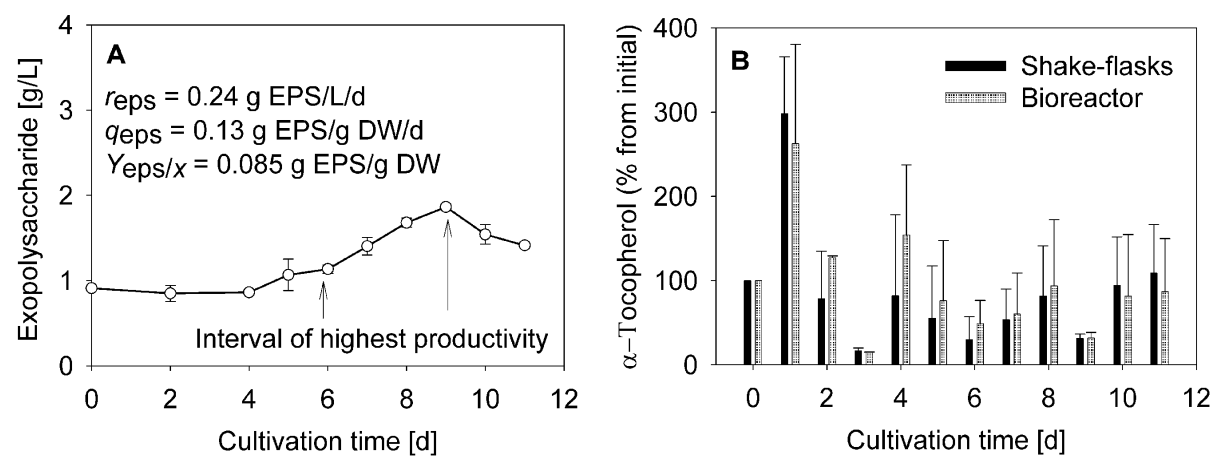

Fig. 3. Time courses of (A) exopolysaccharide production and (B) $\alpha$-tocopherol accumulation during the cultivation of Helianthus annuus cell suspension culture. 
In conclusion, the plant cell suspension culture of sunflower, cultured in stirred tank bioreactor showed stable growth and accumulated high biomass amounts. The cell cycle analysis did not reveal significant changes between bioreactor and shake-flasks cultivation. The production of high value metabolites was proven and the necessity of amounts of optimization of the internal bioreactor environment was outlined.

Cebolla A., Vinardell J. M., Kiss E., Olah B., Roudier F., Kondorosi A., and Kondorosi E. (1999), The mitotic inhibitor ccs52 is required for endoreduplication and ploidy dependent cell enlargement in plants. EMBO J. 18, 4476-4487.

Franke A. A., Murphy S. P., Lacey R., and Custer L. J. (2007), Tocopherol and tocotrienol levels of foods consumed in Hawaii. J. Agric. Food Chem. 55, 769778.

Gala R., Mita G., and Caretto S. (2005), Improving $\alpha$-tocopherol production in plant cell cultures. J. Plant Physiol. 162, 782-784.

Georgiev M., Pavlov A., and Ilieva M. (2006), Selection of high rosmarinic acid producing Lavandula vera MM cell lines. Process Biochem. 41, 2068-2071.

Georgiev M., Pavlov A., and Bley Th. (2007), Hairy root type plant in vitro systems as sources of bioactive substances. Appl. Microbiol. Biotechnol. 74, 1175-1185.

Godoy-Hernandez G. C., Vazquez-Flota F. A., and Loyola-Vargas V. M. (2000), The exposure to trans-cinnamic acid of osmotically stressed Catharanthus roseus cells cultured in 14-1 bioreactor increases alkaloid accumulation. Biotechnol. Lett. 22, 921-925.

Kieran P. (2001), Bioreactor design for plant cell suspension cultures. In: Principles of Multiphase Reactor Design (Cabral J. M. S., ed.). Harwood Academic Publishers, Newark, pp. 391-426.

Kratchanova M., Ilieva M., Pavlova E., Pavlov A., and Markova N. (1996), Immunologically active polysaccharides from cell suspension of Helianthus annuus 1805. In: Progress in Biotechnology - Pectines and Pectinases (Visser J. and Voragen A. G. J., eds.). Elsevier Academic Press, Amsterdam, pp. 679-686.

Marie D. and Brown S. C. (1993), A cytometric exercise in plant DNA histograms, with $2 \mathrm{C}$ values for 70 species. Biol. Cell. 78, 41-51.

Munne-Bosch S. and Alegre L. (2002), The function of tocopherols and tocotrienols in plants. Crit. Rev. Plant Sci. 21, 31-57.

Pavlov A., Werner S., Ilieva M., and Bley Th. (2005), Characteristics of Helianthus annuus plant cell culture as a producer of immunologically active polysaccharides. Eng. Life Sci. 5, 280-283.

\section{Acknowledgements}

This research was supported by a Marie Curie Fellowship of the European Community programme "Development Host Fellowships" under contract number HPMD-CT-2001-00092. The authors express their thanks to Prof. Dr. M. Ilieva (Plovdiv, Bulgaria) for kindly supplying with Helianthus annuus callus culture.

Rao R. S. and Ravishankar G. A. (2002), Plant cell cultures: chemical factories of secondary metabolites. Biotechnol. Adv. 20, 101-153.

Ryu D. D. Y. and Lee S. O. (1990), Determination of growth rate for plant cell cultures: comparative studies. Biotechnol. Bioeng. 35, 305-311.

Schuegerl K. (1981), Oxygen transfer into highly viscous media. Adv. Biochem. Eng. 19, 71-174.

Scragg A. H. (1990), Large-scale cultivation of Helianthus annuus cell suspensions. Enzyme Microb. Technol. 12, 82-85.

Sgorbati S., Sparvoli E., Levi M., and Chiatante D. (1989), Bivariate cytofuorimetric analysis of nuclear protein and DNA relative to cell kinetics during germination of Pisum sativum seed. Physiol. Plant. 75, 479-484.

Shin K.-S., Chakrabarty D., Ko J.-Y., Han S.-S., and Paek K.-Y. (2003), Sucrose utilization and mineral nutrients uptake during hairy root growth of red beet (Beta vulgaris L.) in liquid culture. Plant Growth Regul. 39, 187-193.

Suresh B., Rajasekaran T., Rao S. R., Raghavarao K. S. M. S., and Ravishankar G. A. (2001), Studies on osmolarity, conductivity and mass transfer for selection of a bioreactor for Tagetes patula L. hairy roots. Process Biochem. 36, 987-993.

Werner S. (2005), Investigation of relationships in biological system Helianthus annuus plant cell suspension, nutrient medium and exopolysaccharide. Student Semester Work, Technische Universität Dresden.

Yanpaisan W., King N. J. C., and Doran P. M. (1998), Analysis of cell cycle activity and population dynamics in heterogeneous plant cell suspension using flow cytometry. Biotechnol. Bioeng. 58, 515-528.

Yanpaisan W., King N. J. C., and Doran P. M. (1999), Flow cytometry of plant cells with applications in large-scale bioprocessing. Biotechnol. Adv. 17, 3-27.

Zhong J. J. (2001), Biochemical engineering of the production of plant-specific secondary metabolites by cell suspension cultures. In: Advances in Biochemical Engineering/Biotechnology, Vol. 72, Plant Cells (Scheper T. and Zhong J. J., eds.). Springer, Berlin, Heidelberg, New York, pp. 1-26. 